\title{
A Comparative Study of Maternal and Fetal Outcome in Obese Non- Obese Pregnant Women
}

\author{
ANISA SALEEM ${ }^{1}$, BUSHRA MEHMOOD ${ }^{2}$, AMNA ASLAM $^{3}$, RUBINA KAUSAR $^{4}$ \\ ${ }^{1}$ Senior Registrar Gynae \& Obs, HBS Medical and Dental College, Islamabad. \\ ${ }^{2}$ Assistant Professor Gynae \& Obs department, Shahida Islam Teaching Hospital, Lodhran, \\ ${ }^{3}$ Assistant Professor Gynae \& Obs, Avicena Medical and Dental College, Lahore. \\ ${ }^{4}$ Assistant Professor Gynae \& Obs, Avicena Medical and Dental College, Lahore. \\ Correspondence to: Bushra Mehmood, Email: bushramehmood214@gmail.com, Cell: +92 3346058341
}

\begin{abstract}
Objective: The aim of this study is to determine the adverse pregnancy outcomes in obese and non- obese women. Study Design: Randomized controlled trial

Place and Duration: Department of Gyne \& Obs, Shahida Islam Teaching Hospital Lodhran, during from 01-07-2020 to 31-072021.

Methods: Total one hundred and eighty patients were enrolled in this study. Patients were aged between 18- 50 years. Patients detailed demographics were recorded after taking written consent. Patients were equally divided into two groups I and II. 90 obese patients were included in group I and equally non-obese patients were included in group II. Frequency of pre-eclampsia, gestational diabetes mellitus and post-partum haemorrhage were calculated. Adverse outcomes (cesarean section, instrumental delivery, induction of labor and prolong labor, hypertensive disorder) were also calculated among both groups. Fetal outcomes were perinatal mortality, Low birth weight, Low Apgar score and NICU admission were observed. Complete data was analyzed by SPSS 24.0 version.

Results: Mean age of the patients in group I was $34.12 \pm 4.59$ years with mean BMI $31.12 \pm 8.67 \mathrm{Kg} / \mathrm{m}^{2}$ and in group II mean age was $26.13 \pm 5.78$ years with mean $\mathrm{BMI} 23.03 \pm 9.48 \mathrm{Kg} / \mathrm{m}^{2}$. Frequency of pre-eclampsia in obese group I were high among 40 (44.4\%) patients as compared to group II 9 (10\%) patients, frequency of gestational diabetes mellitus in group I was among 21 $(23.3 \%)$ patients and $6(6.7 \%)$ patients were in group II, post partum haemorrhage was seen in $57(63.3 \%)$ cases in group I and $29(32.2 \%)$ cases in group II. Fetal outcomes, perinatal mortality in group I $5(5.5 \%)$ and in group II was $4(4.4 \%)$, low birth weight in group I was among 21 (23.3\%) and in group II was 45(50\%), low apgar score in group I was 14 (15.5\%) and in group II was $9(10 \%), 43(47.8 \%)$ in group I went to NICU admission and $28(31.1 \%)$ patient in group II admitted to NICU.

Conclusion: Pregnancy-related complications such as gestational diabetes, pre-term labour, and pre-eclampsia are more likely in obese women, according to our data. Having a baby with a woman who is obese might lead to serious difficulties for both mother and baby. Maternal obesity is connected with an increased risk of feto-maternal morbidity and mortality.

Keywords: Pre-eclampsia, Gestational diabetes, Partum haemorrhage, Apgar score, NICU
\end{abstract}

\section{INTRODUCTION}

In recent years, obesity has begun to be considered a global health problem. It is the fifth leading cause of death worldwide. Obesity is a condition of abnormal and excessive fat accumulation in adipose tissue, leading to adverse health effects. The significant contributors to weight gain, which may eventually lead to obesity, are decreased physical activity, increased dietary fat intake, and genetic factors [1]. The rise in obesity is associated with advanced age, which becomes apparent when considering the decrease in older adults' physical activity and metabolic processes. Marital status, high educational level, alcohol use, and high socioeconomic status are other factors associated with obesity [2]. Obesity is measured using various methods, including body mass index (BMI), waist circumference (WC), waist-hip ratio, skinfold, and percent body fat measurements. BMI is the most frequently used diagnostic tool in the current classification system of obesity [3]. It is calculated by dividing weight in kilograms by height in square meters. The World Health Organization (WHO) divided BMI values into six categories to define different body weights, from underweight to obesity. These categories are underweight (less than 18.5), average weight (18.5-24.9), overweight (25.0-29.9), obesity class I (30.0-34.9), obesity class II (35.0-39.9), and obesity class III (40.0 or greater) [4]. Overweight and obesity have become the most general nutritional problems globally, as they impose significant burdens on health care systems. Obesity affects 2.1 billion people (almost one-third) in the world. If the current trend continues, this figure may reach nearly half of the world's adult population by 2030 [5].

Moreover, obesity is associated with multiple diseases and may result in the death of millions of people every year. Furthermore, the risk of non-communicable diseases (NCD), such as hypertension (HTN), type 2 diabetes mellitus (T2DM), dyslipidemia, and cardiovascular disease (CVD), increases dramatically with obesity. Besides, obstructive sleep apnea and osteoarthritis relate to obesity [6]. Females were to have a higher rate of obesity. Its prevalence doubled between 1980 and 2008, from $8 \%$ in 1980 to $14 \%$ in 2008. The highest incidence of overweight and obesity in 2013 was in North Africa and the Middle East, where more than $65 \%$ of reproductive-age females were overweight or obese [6]. According to a study of overweight and obesity in Saudi women of childbearing age, the following rates of obesity were found: $22.4 \%$ were obesity class I, $11.1 \%$ were obesity class II, and $6.6 \%$ were morbidly obese (obesity class III) [6]. Furthermore, Saudi women have exceptional obstacles that can predispose them to a sedentary lifestyle, such as the essential wearing of abaya or full-length overgarment in public, gender segregation, and activities that are primarily at home $[7,8]$. Maternal obesity is one of the central risk factors for adverse pregnancy outcomes, including gestational diabetes mellitus (GDM), operative delivery, and stillbirth [9]. The prevalence of hypothyroidism among Saudi pregnant women is $13 \%$, most of them were in their third trimester [10].

Maternal obesity increases perinatal mortality, which increases the risk of perinatal death and preterm birth, macrosomia, congenital anomaly, childhood obesity, and stillbirth. Also, maternal obesity is related to a higher risk of cesarean deliveries and a higher incidence of anesthetic and postoperative complications. Another major complication is preeclampsia, a specific syndrome characterized by new onset of hypertension with proteinuria that occurs after 20 weeks gestation. The actual cause of preeclampsia is unknown, but it is estimated to affect 2 to $8 \%$ of all pregnancies $[11,12]$.

The purpose of this study is to determine the adverse pregnancy outcomes in obese and non- obese women.

\section{MATERIAL AND METHODS}

This randomized control trial was conducted at- Department of Gyne \& Obs, Shahida Islam Teaching Hospital Lodhran, during 
from $01-07-2020$ to $31-07-2021$ and comprised of 180 patients Patients detailed demographics were recorded after taking written consent. Patients with placenta previa, history of recurrent miscarriages, previous uterine scars were excluded from this study.

Study was conducted after approval from the Ethical Committee of the Institution. Patients were equally divided into two groups I and II. Group had 90 obese patients and group II was with hundred non-obese patients. Patient's BMI was measured by obtaining height and weight in the outpatient department. Patients were followed till delivery. The outcome variable (i.e. preeclampsia, gestational diabetes mellitus and post-partum haemorrhage) were noted in the Performa by the researcher. Adverse outcomes (cesarean section, instrumental delivery, induction of labor and prolong labor,) were also calculated among both groups. The mean and standard deviation for patients' age and gestational ages have been determined using descriptive statistics. The outcome variables, i.e. preeclampsia, gestational diabetes mellitus, and postpartum bleeding were measured at rates and percentages. Fetal outcomes were perinatal mortality, Low birth weight, Low Apgar score and NICU admission were observed. Complete data was analyzed by SPSS 24.0 version.

\section{RESULTS}

Mean age of the patients in group I was $34.12 \pm 4.59$ years with mean BMI $31.12 \pm 8.67 \mathrm{Kg} / \mathrm{m}^{2}$ and in group II mean age was 26.13 \pm 5.78 years with mean BMl $23.03 \pm 9.48 \mathrm{Kg} / \mathrm{m}^{2}$. Mean gestational age of group I was $36.71 \pm 4.44$ weeks while in group II mean gestational age was $37.08 \pm 3.51$ weeks. Mean parity in-group I was $5.03 \pm 3.22$ while in group II it was $4.11 \pm 2.41$. (table1)

Table 1: Baseline detailed demographics of presented patients

Table 1: Baseline detailed demographics of presented patients
\begin{tabular}{|l|l|l|}
\hline Variables & Group I & Group II \\
\hline Mean age (years) & $34.12 \pm 4.59$ & $26.13 \pm 5.78$ \\
\hline Mean BMI & $31.12 \pm 8.67$ & $23.03 \pm 9.48$ \\
\hline Gestational age (weeks) & $36.71 \pm 4.44$ & $37.08 \pm 3.51$ \\
\hline Mean Parity & $5.03 \pm 3.22$ & $4.11 \pm 2.41$ \\
\hline
\end{tabular}

Frequency of pre-eclampsia in obese group I were high among $40(44.4 \%)$ patients as compared to group II 9 (10\%) patients, frequency of gestational diabetes mellitus in group I was among $21(23.3 \%)$ patients and $6(6.7 \%)$ patients were in group II, post partum haemorrhage was seen in $57(63.3 \%)$ cases in group I and $29(32.2 \%)$ cases in group II. (table 2$)$

Table 2: Frequency ofpre-eclampsia, Gestational Diabetes and Post Partum Haemorrhage among study cases

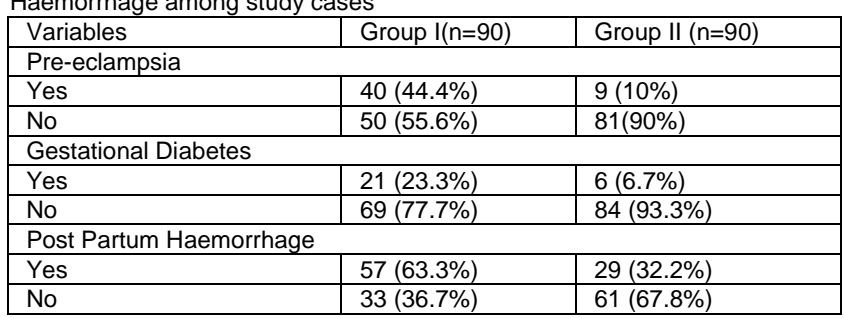

Table 3: Frequency of adverse outcomes among both groups

Table 3: Frequency of adverse outcomes among both groups
\begin{tabular}{|l|l|l|}
\hline Maternal Outcomes & Group I & Group II \\
\hline Cesarean section & $30(33.3 \%)$ & $10(11.11 \%)$ \\
\hline Instrumental delivery & $9(10 \%)$ & $4(4.4 \%)$ \\
\hline Induction of labor & $19(21.1 \%)$ & $7(7.8 \%)$ \\
\hline Prolong labor & $8(8.9 \%)$ & $2(2.2 \%)$ \\
\hline Fetal Outcomes & & \\
\hline Perinatal mortality & $5(5.5 \%)$ & $4(4.4 \%)$ \\
\hline low birth weight & $21(23.3 \%)$ & $45(50 \%)$, \\
\hline low apgar score & $14(15.5 \%)$ & $9(10 \%)$ \\
\hline NICU admission & $43(47.8 \%)$ & $28(31.1 \%)$ \\
\hline
\end{tabular}

Frequency of adverse outcomes (cesarean section, instrumental delivery, induction of labor and prolong labor,) in obese group were significantly higher than that of non-obese. Fetal outcomes, perinatal mortality in group I $5(5.5 \%)$ and in group II was $4(4.4 \%)$, low birth weight in group I was among 21 (23.3\%) and in group II was $45(50 \%)$, low apgar score in group I was 14 $(15.5 \%)$ and in group II was $9(10 \%), 43(47.8 \%)$ in group I went to NICU admission and $28(31.1 \%)$ patient in group II admitted to NICU. (table 3)

\section{DISCUSSION}

In many cases, obesity is a substantial contributor to increased morbidity and death, such as heart disease, type 2 diabetes, and cancer. Pre-eclampsia, premature births, gestational diabetes, and caesarean deliveries are all elevated when a woman is obese during pregnancy. These perinatal difficulties are exacerbated by a lack of treatment options that address the root causes of these issues. Women planning their first pregnancies are more at risk from the effects of obesity, according to recent epidemiological studies.

In this study 180 pregnant obese and non-obese women were presented. Patients were equally divided into two groups I and II. 90 obese patients were included in group I and equally nonobese patients were included in group II. Pre-eclampsia was observed $44.4 \%$ in obese group was greater than that of nonobese group $10 \%$. These results were comparable to the previous study conducted by Ahmed SR et al. [11] According to findings from this study, the majority of obstetric complications are more likely to occur in obese women than in non-obese women, with the exception of hyperemesis gravidarum, which is more common in obese women. According to Doherty et al, obese women are 1.5 times more likely to suffer from hyperemesis gravidarum than nonobese women. [12] Pregnancy-related hypertension and preeclampsia are more common among obese women, according to our research.

In our study gestational diabetes mellitus was higher $23.3 \%$ in obese patients as compared to non-obese $6.7 \%$. In other study gestational diabetes mellitus was significantly more common in obese pregnant women (odds ration (99\% confidence interval) for BMI $25-30$ and $\mathrm{MBI} \geq 30$ respectively $(1.53-1.84)$, 3.6 (3.253.98). [13,14] Frequency of post-partum haemorrhage in obesity patients were $63.3 \%$ relatively greater than that of control group patients $32.2 \%$. [15-17]

The rate of cesarean delivery in obese group was $33.3 \%$, a higher percentage as compared to the rate of cesarean sections in group I was $11.11 \%$, these results were greater than that of studies conducted in the Portuguese NHS hospitals in 2016 (23.5\%). [18] In this study, the amount of adverse effects to instrumental delivery, prolonged work and labour induction (10\%, 8.9\%, $21.1 \%)$ was higher than usual classes. GD and GD are both independent factors of concern for cesaricdelivery[19,20]. The growing obesity epidemic, in order to have an effect both of maternal hyperglycemia and obesity, is important to compare pregnancy results in overweight and obese women with and without GD. Martin and cols, for example. In the obesity women who were independent of GD. [21]Blickstein and cols indicated an increased risk of caesarean delivery and LGA newborns. Fetal outcomes, perinatal mortality in group I $5(5.5 \%)$ and in group II was $4(4.4 \%)$, low birth weight in group I was among $21(23.3 \%)$ and in group II was $45(50 \%)$, low apgar score in group I was $14(15.5 \%)$ and in group II was $9(10 \%), 43(47.8 \%)$ in group I went to NICU admission and $28(31.1 \%)$ patient in group II admitted to NICU. Only obesity [22] and, more recently, Huett\& Colls were affected by the possibility of preeclampsia and macrosomia. The risk of macrosomal disease in obese women without GD is higher compared with GD and the risk of caesarean section substantially increases and maternal morbidity is considerably higher in obese women irrespective of diabetes regulation.[22]

\section{CONCLUSION}

Pregnancy-related complications such as gestational diabetes, pre-term labour, and pre-eclampsia are more likely in obese 
women, according to our data. Having a baby with a woman who is obese might lead to serious difficulties for both mother and baby. Maternal obesity is connected with an increased risk of fetomaternal morbidity and mortality.

\section{REFERENCE}

1. DeNicola, E.; Aburizaiza, O.S.; Siddique, A.; Khwaja, H.; Carpenter, D.O. Obesity and public health in the Kingdom of Saudi Arabia. Rev. Environ. Health 2015, 30, 191-205

2. Paul, E.; Mtumwa, A.H.; Ntwenya, J.E.; Vuai, S.A.H. Disparities in Risk Factors Associated with Obesity between Zanzibar and Tanzania Mainland among Women of Reproductive Age Based on the 2010 TDHS. J. Obes. 2016, 2016, 1-10.

3. Gómez-Ambrosi, J.; Silva, C.; Galofré, J.C.; Escalada, J.; Santos, S.; Millán, D.; Vila, N.; Ibañez, P.; Gil, M.J.; Valentí, V.; et al. Body mass index classification misses subjects with increased cardiometabolic risk factors related to elevated adiposity. Int. J. Obes. 2012, 36, 286294.

4. Othman, M.; Himayda, S.S.; Shaaban, L. Obesity and Pregnancy in Saudi Women. Arch. Clin. Med. Case Rep. 2018, 2, 50-55.

5. Saudi Ministry of Health. The National Guidelines for Management of Cardio-Metabolic Risk Factors in Primary Health Care; Saudi Ministry of Health: Saudi Arabia, 2014.

6. Aljabri, K.S.; Bokhari, S.A.; Khan, A.; Ebu Elsaoud, H.M.; Aljabri, B.K.; Boraie, R.E. Overweight and Obesity in Saudi Women of Childbearing Age. Endocrinol. Metab. Res. 2018, 3, 53-62.

7. Al-Hamdan, R.; Avery, A.; Salter, A.; Al-Disi, D.; Al-Daghri, N.M.; McCullough, F. Identification of Education Models to Improve Health Outcomes in Arab Women with Pre-Diabetes. Nutrients 2019, 11 1113.

8. Mirabelli, M.; Russo, D.; Brunetti, A. The Role of Diet on Insulin Sensitivity. Nutrients 2020, 12, 3042.

9. Ali, H.S.; Lakhani, N. Effect of obesity and its outcome among pregnant women. Pak. J. Med. Sci. 2011, 27, 1126-1128.

10. Alshahrani, M.; Alqahtani, N.; Alqahtani, A.; Almaqbul, W.; AlWadei, A.; Alzamanan, S.; Salhi, A.; Musallam, S.; Almoqati, S.; Alyami, A. et al. Overweight and obesity awareness before pregnancy in Najran, Saudi Arabia. Int. J. Med Sci. Public Heal. 2018, 7, 1.
11. Ahmed SR, Ellah MA, Mohamed OA, Eid HM. Prepregnancy obesity and pregnancy outcome.Int J Health Sci (Qassim). 2009;3(2):203208.

12. Doherty dA, Magannef, Francis j, Morrison JC, Newnham JP.Prepregnancy body mass index and pregnancy outcomes.International Journal of Gynecology and Obstetrics. 2006;95:242-247.

13. Sebire NJ, Jolly M, Harris JP, Wadsworth J, Joffe M, Beard RW, et al Maternal obesity and pregnancy outcome: a study of 287,213 pregnancies in London. Int J Obes. 2001;25:1175-82.

14. Athukorala, C., Rumbold, A.R., Willson, K.J. et al.The risk of adverse pregnancy outcomes in women who are overweight or obese.BMC Pregnancy Childbirth 10, 56 (2010). https://doi.org/10.1186/14712393-10-56

15. Miao M, Dai M, Zhang Y, Sun F, Guo X, Sun G. Influence of maternal overweight, obesity and gestational weight gain on the perinatal outcomes in women with gestational diabetes mellitus. Sci Rep. 2017;7(1):305.

16. Blickstein I, Doyev R, TrojnerBregar A, BrzanSimenc G, Verdenik I, Tul N. The effect of gestational diabetes, pre-gravid maternal obesity, and their combination ('diabesity') on outcomes of singleton gestations. J Matern Fetal Neonatal Med. 2018;31(5):640-3.

17. WHO Recommendations for Prevention and Treatment of PreEclampsia and Eclampsia. WHO Guidelines Approved by the Guidelines Review Committee. Geneva; 2011

18. Instituto Nacional de Estatística IP. Estatísticas da Saúde 20162018 [updated 24 may 2018].

19. Martin KE, Grivell RM, Yelland LN, Dodd JM.The influence of maternal BMl and gestational diabetes on pregnancy outcome.Diabetes Res ClinPract. 2015;108(3):508-13.

20. Huet J, Beucher G, Rod A, Morello R, Dreyfus M. Joint impact of gestational diabetes and obesity on perinatal outcomes. J GynecolObstet Hum Reprod. 2018;47(9):469-76.

21. Davies-Tuck, M.; Mockler, J.C.; Stewart, L.; Knight, M.; Wallace, E.M. Obesity and pregnancy outcomes: Do the relationships differ by maternal region of birth? A retrospective cohort study. BMC Pregnancy Childbirth 2016, 16, 288.

22. 10. Al Shanqeeti, S.A.; Alkhudairy, Y.N.; Alabdulwahed, A.A. Ahmed, A.E.; Al-Adham, M.S.; Mahmood, N.M. Prevalence of subclinical hypothyroidism in pregnancy in Saudi Arabia. Saudi Med. J. 2018, 39, 254-260. 